\title{
ENGINEERING ASSESSMENT OF KARST SINKHOLE CAUSATION AND PREDICTION IN LITIGATION
}

Michael J. Byle

Tetra Tech, Inc., One Oxford Valley, Suite 200, Langhorne, PA 19047, USA, michael.byle@tetratech.com

\begin{abstract}
Sinkholes in karst environments can cause damage to facilities and structures and pose a health and safety risk. The occurrence of sinkholes is difficult to predict and poses liability to planners, designers, owners, and engineers who practice in these areas. Often times the occurrence of sinkholes leads to litigation over who is responsible and who should have anticipated and designed mitigation to prevent consequences of sinkholes. Where performance does not meet with expectations, individuals are put at risk, or where damage occurs, litigation frequently ensues. The critical components of the litigation often revolve around causation, predictability, and cost to remediate and/or prevent future sinkholes.
\end{abstract}

Causation is important to identify responsible parties. Since the number of factors that influence the frequency, severity, and locations of sinkholes are many and involve geology, geotechnical engineering, surface water hydrology, and groundwater hydrology, a multidisciplinary approach is needed. A logical and prioritized basis is best to assess the relative merits of various mechanisms and determination of the one or two primary factors that either caused a condition to develop, or exacerbated an existing condition, and those factors that could reasonably have been anticipated using the appropriate standard of care. From an engineering perspective, it is essential to understand the causative factors to develop and estimate the costs for mitigation and restoration. The presentation will address the factors important to this assessment and approach to prioritization to deduce the key causative factors for covered carbonate karst. The presentation will also address the measures to identify the certainties and address the uncertainties in karst conditions for litigation.

\section{Consequences of Unanticipated Karst}

Litigation issues related to sinkholes in karst focus on their unanticipated occurrence. The potential impacts of unanticipated karst features are manifold. These include the potential for delays, and cost overruns where they are discovered in construction, as well as failures after construction that can cause a variety of damages including: property damage, injury, loss of use, environmental damage and loss of life. Sinkholes can result in groundwater contamination with sediment, or releases of chemicals, extending broadly and widely. A sinkhole almost anywhere can be a safety hazard for injury or loss of life even in open fields. A sinkhole in a parking lot can damage automobiles, injure individuals, damage utilities and impair use of the property. A sinkhole forming under a structure results in loss of support for the structure that can lead to building damage or collapse. Even when karst conditions are known, specific occurrences may be unanticipated where investigations, assessments, and mitigations are not sufficient.

\section{Uncertainty in Karst}

Risk analysis has been applied to subsidence risk in karst (Kaufmann, 2008; Doctor et al., 2008, Perlow, 2008, Zisman, 2008, etc). Most of this type of work has been focused on development risk and not on identifying the specific risk of karst features being present at any specific location, though similar approaches can be used, provided sufficient site-specific data is available. There are a number of categories of uncertainty associated with the investigation and design for a successful project outcome. These can be divided into site uncertainties, methodological uncertainty and temporal behavior uncertainty.

For the purposes of this discussion, the term site uncertainties is defined as those unknown conditions present in the subsurface of the site that will affect the potential for sinkholes to form. Site uncertainties would affect the type and distribution of subsidence and the number of sinkholes that could be expected at a site and the decisions made to mitigate risk of sinkhole formation. The site uncertainties include site geologic variability, formational structural variability (i.e. the occurrence of fractures, folds or other features), the degree of weathering and karstification, the maturity of the karst, the presence of infilling, caves, etc., as well as, the depth and condition of soil overburden and the geohydrologic conditions.

\section{Geology}

Geological uncertainty relates to the nature of the formation as defined in geologic terms. That is the type 
of rock, rock material properties. This occurs where the nature of the geologic formation is either not known, or poorly defined.

An example of this would be the situation where a formation is mapped that consists of alternating beds of differing rock types, without a defined sequence or where bedrock mapping is incomplete. Bedrock mapping is often incomplete where it is overlain by a thick mantle, or where surface geomorphology is not residual, such as where the karst stratum is overlain by alluvium, glacial deposits, or other such regolith that would mask the presence and nature of the underlying bedrock. This can obscure contacts between formations. Another instance of geologic uncertainty would be where complex faulting or folding results in local disruption of the regional geology that may not be completely mapped.

\section{Structure}

Structural uncertainty refers to uncertainty related to the geologic structure. This includes location and condition of joints, faults, as well as, voids in the bedrock formation which comprise the secondary porosity of the formation. Structural geology informs the search for voids, since solution is typically more pronounced in areas of higher transmissibility where rock is fractured or broken and along discontinuities such as unconforming geologic contacts. Resolving or reducing structural uncertainty probably has the greatest impact on assessing sinkhole risks for a site.

\section{Hydrology}

Hydrologic uncertainty arises from complexity of groundwater flow in karst. The impact of groundwater hydrology on the environmental risks is profound; even a small opening can carry much flow (Fig 1). Hydrology of the karst is also critical where below-grade construction may penetrate the water table, since karst conduits can make many dewatering methods impractical. Likewise, surface water hydrology also presents uncertainties, since infiltration pathways for surface water may not be well known and will influence karst processes.

\section{Geomorphology}

Geomorphology is the study of the processes, characteristics and configuration and evolution of rocks and landforms. It is important to know what stage of the geomorphologic process the formation is in. Karstification is a geomorphologic process involving many stages from the initial dissolution of rock

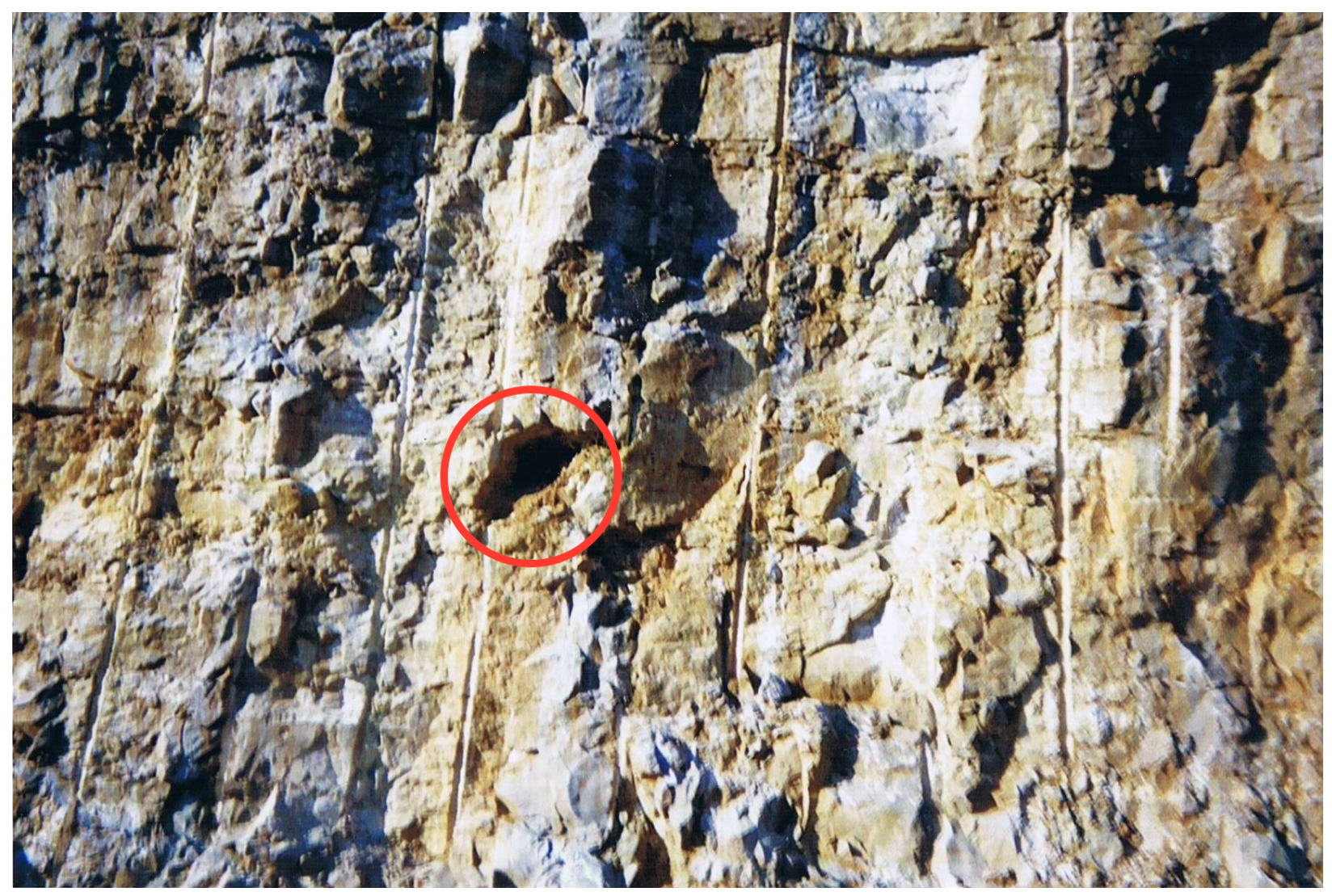

Figure 1. Isolated karst conduit in otherwise intact rock 
minerals, and formation weathering, to the erosion and infilling of voids, to the ultimate decomposition of the rock matrix. Understanding this process in a particular formation is necessary to assess whether voids are active conduits, plugged paleo-karst, or something in between. An excellent discussion of karst conditions and their formation is included in Waltham et al. (2005) and White (1988).

\section{Investigation Methodology}

The application of different methodologies will result in differing degrees of certainty when interpreting the results. If the geology, structure and geomorphology are sufficiently understood, appropriate investigational tools may be selected to assure the required information is obtained to assess the sinkhole risk at a site. It is critical to understand the limitations of the methods being used to properly assess the level of uncertainty with respect to the presence or absence of features. It is important to recognize that no method, short of complete removal of soil (regolith) over the top of rock, could fully disclose all openings in the top of rock.

\section{Forensic Assessment}

When a sinkhole has formed, some degree of uncertainty is removed, since the sinkhole itself provides evidence of subsurface conditions. Forensic studies usually include the following assessments:
A. Condition and consequences
B. Mitigation/repair
C. Potential for recurrence
D. Causation Assessment
E. Responsible Parties

Forensic assessments are subject to all of the same limitation as any other investigation, though there are several advantages. Forensic investigators have the knowledge that something has indeed occurred, eliminating the need for speculation on the potential for something to occur. In litigation, the forensic investigator has the advantage of seeing all of the evidence revealed by the discovery process, providing a more circumspect view having information that may not have been available to all of the parties to the case. This can provide an improved picture, but will not remove all of the uncertainties outlined in the foregoing section. Regardless, it is important that the investigation extend beyond the limits of the sinkhole feature itself in order to establish the context and to provide a basis to assess what caused the sinkhole to open where it did and when it did. Investigation should assess a broad range of factors related to sinkhole causation including a thorough characterization of the surface and subsurface conditions at the site, as well as, historical review to establish context in the timeline of events.

Definition of responsibility is probably the most difficult of all tasks. This assessment requires understanding of the standard of care. When it comes to karst, the standard of care can vary significantly from region to region and among the various disciplines involved in investigation, evaluation, and design in karst environments. Geologists, engineers, geophysicists, and hydrogeologists all look at karst from different perspectives. Often the lines of responsibility become blurred where one professional is relying on the work of another; such as an engineer basing a design on the work of a geologist, who in part forms his recommendations based on the work of a geophysicist. It is important to fully understand the relationships and responsibilities of the parties from a legal perspective and to understand the communications among the parties, as improper sharing of information is often a factor in these cases.

\section{Finding Certainty in Karst}

Resolving conflicts involving sinkholes in karst requires that the actions or inactions of the various parties be evaluated in light of the consequences they cause. Even where it is given that all karst features cannot be defined in covered karst, there remain actions that are certain to increase or induce sinkhole formation. The timeframe in the life of the karst formation is important to understand. In carbonate rock, active dissolution of the rock is usually not a consideration; whereas, in most instances openings are present within the carbonate rock below the regolith (soil overburden). At some point in the process, voids form in the regolith as soil grains are eroded and transported into the underlying voids.

Accordingly, there are three basic conditions that must exist to cause soil migration leading to the formation of collapse sinkholes in covered karst. These are: 1) hydraulic gradient sufficient to erode and transport soil, 2) pathways in the rock through which soil is transported, 3) place for transported soil to go. If any one of the three is missing, collapse sinkhole formation is improbable at best.

The regolith is eroded and transported by water. Water cannot erode or transport soil unless it is under a gradient that induces flow. Hydraulic gradients are the result of different water levels within the formation, but may be induced by manmade means through irrigation, modifying surface drainage, or altering groundwater levels through dewatering, or water injection. The highest gradients exist where water is free to fall under gravity. Such conditions exist where the static ground 
water level is well below the ground surface and below the top of rock, where seepage of infiltrating water encounters a free surface of an unsaturated void. This condition leads to erosion of the soil grains at the free surface that progressively enlarges the cavity in a process known as piping. If all else is equal at a site, changes that lead to increased gradients, particularly through lowering of the static groundwater below the top of rock may nearly always be considered causative.

The absence of openings in the rock that serve as pathways for transport of material will preclude the formation of collapse sinkholes in covered karst. Obstructed openings will have a similar effect, but these can be cleared or flushed to open a pathway that was previously closed. Such can happen when excavations or mining operations expose the lower end of a filled karst feature and water seepage, either over time, or due to a sudden inflow that flushes the opening. The infilling material provides hydraulic resistance flattening the gradient due to its permeability. If it is removed, the gradient increases and can activate soil movement to enhance sinkhole formation.

Even if there is a gradient and pathway, there must be openings of a size equal to, or greater than, the volume of regolith that must be eroded to cause a sinkhole. Thus, small closed openings will fill and stop the process before collapse can occur. A manmade condition, such as where mining, or excavation exposes a karst feature or conduit, can create a new location for discharge and deposition of sediments carried by water flowing through the karst features. Such situations can be an incipient cause of sinkholes.

\section{Assessing Causality and Responsibility}

The first step in evaluating responsibility begins with reviewing the site investigations. Recognizing the uncertainties in karst, the key is not in determining whether all features were identified, but rather, were the karst conditions identified and associated risks explained. The adequacy of the investigation is also a factor, but depends on many factors related to contracting and communication. Investigation should be adequate to identify conditions necessary to assess the site conditions, but may be limited where karst is unanticipated, or where the full extent and nature of the project evolves after the initial investigation. Having a geologic, or geotechnical report that makes no mention of karst in a known karst area, generally increases the potential for karst liability for consultants.

It must be recognized that a few borings, or lines of surface geophysics, cannot prove that there is no sinkhole risk. Proper use of the tools and interpretation of the results is essential to limiting professional liability in karst sites. Language that minimizes the consequences of karst without sufficiently detailed evaluation can open the door to design, construction, and land uses that induce sinkholes.

The second step is to assess whether appropriate measures were taken to mitigate the identified risks, or whether the owner of the project elected to assume those risks without mitigation. Sometimes, the clarity with which the risks are communicated becomes a significant factor in these cases. A project designer who ignores the karst related issues may well be assuming additional liability.

Even when all of the work on a project is done correctly, third party actions may cause or enhance the formation of sinkholes in covered karst. Identifying a manmade cause is essentially sorting out the activities undertaken by the various parties and assessing them in light of how they affected the sinkhole formation process. Such activities as installing a ground water supply well, tunneling, excavating a deep roadway cut, quarrying, and mining can alter the groundwater.

Evaluating causation is a multipronged process. There are always multiple factors that must work in concert for conditions to produce a sinkhole collapse. In some instances, comparison of conditions at one location to a similar site elsewhere may be considered to demonstrate either how an action either does or does not influence sinkhole occurrence. Extreme caution should be used when considering such an approach. While a site may look similar on the surface, many factors will make it differ. Karst in any location is unique. Differing factors may include:

$\begin{array}{lll}\text { - history of land use } & \bullet \text { vegetation } \\ \text { - history of groundwater } & \bullet \text { topography } \\ \text { withdrawal } & \bullet \text { degree of } \\ \text { - stratigraphy } & & \text { karstification } \\ \text { - faulting, fracturing, and } & - \text { geochemistry } \\ \text { - bedding } & - \text { groundwater } \\ \text { - } \text { surface hydrology } & \text { hydrology }\end{array}$

Any of these factors in itself or in combination with other factors can make a significant difference in the potential for sinkhole occurrence. All of the factors should be assessed before accepting another site as comparable.

A logical step-by-step approach is needed to assess cause and effect and to evaluate relative impacts. Time can be a measure of proof, where it can be shown that a sinkhole event is closely timed to a particular action, however, it 
is also necessary to define the causative link in technical terms. It is extremely difficult to isolate one sinkhole occurrence and identify unique causation for it where multiple sinkholes have occurred in the surrounding area over time, independent of a specific cause. However, if sinkholes begin to form after an event that changes conditions to enhance sinkhole formation, there will be a better case to establish causation. A legal basis can be made where it can be shown, that but for a specific event, such as groundwater level depression or surface water diversion, sinkholes either would not have occurred, or would have been far less likely.

\section{Standard of Care}

The value of a prediction depends on the skill and care exercised in preparing the prediction. When the predicted behavior does not occur, negligence of the professional may be the basis of a litigation. The basis for establishing negligence in a tort case is based on a failure to exercise the care and skill that is ordinarily exercised by other members of the engineering profession in performing professional engineering services under similar circumstances (Dal Pino 2014). This is often referred to as the standard of care.

Establishing the standard of care in karst conditions can be challenging, since geologists and engineers often have different perspectives and some practitioners in karst have widely differing views on assessing and mitigating karst conditions. This interdisciplinary nature of karst makes the establishment of a single standard difficult.

Local practices differ from state to state and region to region based on local experience. Some geotechnical consultants involved in a karst project may have limited experience and may not have the depth of knowledge necessary to properly assess conditions, while others may have extensive depth of experience and capability. Despite following the standard of care they would normally use for other projects, different outcomes may be achieved. This raises the question as to when specialty services are required. The complexity, which can be much greater than typical sites, and the level of knowledge of geology and hydrogeology, require an understanding and application of fundamental soil mechanics at a higher level than would be typical of common practice. Specialists and experts are held to a different standard that is based on the performance of reasonable experts rather than common practice.

The fundamental question regarding the standard of care relates to the requirement that the comparison be made for "similar circumstances". The high variability within karst automatically makes it different from most other geologies and makes it difficult to assess what comprises care and skill that are ordinarily practiced. The standard of care is assessed state by states in rules, regulations and legal precedents and is not uniform nationwide.

Assessing a case with regard to compliance with the standard of care is especially challenging and requires special evaluation to establish the appropriate standard of care. It is important to define the role of the consultant(s) and review local and regional practices, as well as state requirements. Once these have been established, a comparison can be made for initial assessment. Detailed evaluation of contracts, correspondence, reports, and other communications is necessary to shed light on the roles played by the parties to a case and to improve the initial assessment.

A further complication in assessing negligence, is that the project facts and sequence of events can affect the roles of the parties as the project progressed. Predictions and decisions that appear reasonable at the time they were made, may be changed by new conditions disclosed at a later time. Seemingly simple changes to a site plan, such as relocating stormwater structures, can greatly affect the risk of sinkhole occurrence in a way not anticipated by the geotechnical engineer and unknown to the civil designer. Such situations can lead to defective performance even though both parties performed within their respective standard of care. Such instances illuminate the need for good communications of the nature of the risks throughout a design team that can be thwarted by the compartmentalized design and construction processes used on many projects.

\section{Specialties in Conflict}

Even given the same circumstances, geologists and engineers will often come to different conclusions. Geologists are scientists and base their recommendations on their experience and scientific judgement. Engineers work in applied science and base their recommendations on engineering design principals. While the two approaches may lead to consistent recommendations in some cases, but in others, they may not. Engineers are knowledgeable in geotechnical, structural, and construction aspects of the work that geologists are not. On the other hand, geologists may have specific knowledge about geologic structure, geomorphology, and hydrogeology that many engineers may not. In truth, neither can know the whole picture without input from the other.

Often, owners and developers will select the recommendation that leads to the outcome they desire and will tend, when given a choice, to select the 
consultant that tells them what they want to hear. This is especially important where the recommendation will cost a lot of money.

Roger Brucker is a noted cave explorer and karst cave expert. In a 2014 article in GeoStrata magazine (Brucker, 2014), he cites a case where an expert warned of an underground karst cave and recommended routing a roadway around the area of thin roof rock. The developer ignored that recommendation, and constructed the road over the cavity that subsequently collapsed. At the conclusion of the article Mr. Brucker eschews mitigation measures and recommends avoiding development on karst altogether, while clearly that was not the recommendation of the developer's consultant. If one expert's recommendation is avoidance and another expert's recommendation is mitigation, or even normal practices with no special measures, the client is left to choose who to believe.

A team approach can resolve this. In karst work that the author has performed, both a karst geologist and a geotechnical engineer are typically included as a team. This approach gives the best of both disciplines and is essential to get a complete picture. Defining the cause of a sinkhole is dependent on understanding the geology and engineering measures taken in the process to determine who or what may be at fault.

\section{Conclusion}

Evaluating karst requires special knowledge and attention to detail to identify and characterize the mechanisms at work a given site. It is not necessary to eliminate all uncertainties in the site conditions for a forensic assessment of causation in karst. It is only necessary to characterize conditions sufficiently to identify key factors that affect hydraulic gradients, pathways, and discharge of sediment. Establishing a traceable link from a specific action to changes in these factors is the primary basis to establish a causal relationships to that action. The causative action can be anything such as relocating a stream, actively withdrawing ground water, mining, site development, etc. Identification of the effects of the action, either directly or indirectly, and relating them to the key factors in sinkhole formation, can be the basis to establish causation, or demonstrate the irrelevance of an action. A team including an engineer and geologist can provide the best approach to investigation and evaluation of sinkhole occurrence and causation.

\section{References}

Brucker, Roger (2014) "Report from an Underground World”, GeoStrata, November/December 2014, ASCE pp. 18-20.

Dal Pino, John, (2014) Do You Know The Standard of Care? - CASE White Paper 2014, American Consulting Engineers Council, Washington, DC.

Doctor K.Z., Doctor, D. H., Kronenfeld, B., Wong, W.S., and Brezinski, D. K. (2008) "Predicting Sinkhole Susceptibility in Frederick Valley, Maryland Using Geographically Weighted Regression." Published in Sinkholes and the Engineering and Environmental Impacts of Karst; Proceedings of the Eleventh Multidisiplinary Conference, ASCE Geotechnical Special Publication No. 183, Reston, VA, 243-256.

Kaufmann, James E. (2008) "A statistical approach to Karst Collapse Hazard Analysis in Missouri." Published in Sinkholes and the Engineering and Environmental Impacts of Karst; Proceedings of the Eleventh Multidisiplinary Conference, ASCE Geotechnical Special Publication No. 183, Reston , VA, pp 257-268.

Perlow, Michael Jr. (2008) "Knowledge Based Geologic Risk assessment for Municipal, Transportaion, Energy, and Industrial Infrastructure" Published in Sinkholes and the Engineering and Environmental Impacts of Karst; Proceedings of the Eleventh Multidisiplinary Conference, ASCE Geotechnical Special Publication No. 183, Reston, VA, pp 233-242.

Waltham, Tony, Fred Bell, and Martin Culshaw, (2005) Sinkholes and Subsidence: Karst and Cavernous Rocks in Engineering Construction. SpringerPraxis, Chichester, UK

White, William B. (1998) Geomorphology and Hydrology of Karst Terrains. Oxford University Press, New York, NY

Zisman, E.D. (2008) "A Method for Quantifying Sinkhole Risk." Published in Sinkholes and the Engineering and Environmental Impacts of Karst; Proceedings of the Eleventh Multidisiplinary Conference, ASCE Geotechnical Special Publication No. 183, Reston, VA, pp 278-287. 